\title{
HYDROPHOBIC INTERACTION CHROMATOGRAPHY OF ALIPHATIC ALCOHOLS AND CARBOXYLIC ACIDS ON OCTYL-SEPHAROSE CL-4B: MECHANISM AND THERMODYNAMICS
}

\author{
W. J. GELSEMA*, P. M. BRANDTS, C. L. DE LIGNY, A. G. M. THEEUWES and A. M. P. ROOZEN \\ Analytical Chemistry Laboratory, State University of Utrecht, Croesestraat 77A, 3522 AD Utrecht (The \\ Netherlands)
}

(First received October 19th, 1983; revised manuscript received February 16th, 1984)

\section{SUMMARY}

The retention of homologous aliphatic alcohols and carboxylic acids in dilute phosphate buffer solution was measured on octyl-Sepharose CL-4B and on unsubstituted Sepharose CL-4B as a function of chain length, $\mathrm{pH}$ and temperature. From the retention data the standard thermodynamic functions $\left(\Delta G^{\circ}, \Delta c_{p}^{\circ}, \Delta H^{\circ}, \Delta S^{\circ}\right)$ of the interaction were calculated. The thermodynamics and mechanism of the retention process are discussed.

\section{INTRODUCTION}

Hydrophobic interaction chromatography is a relatively new separation method that is rapidly finding applications in biochemistry. As it exploits a parameter, i.e. hydrophobicity, that is not directly used in the common separation methods based on differences in electrical and size parameters, it is a welcome additional tool in the biochemist's laboratory. With the introduction of uncharged alkyl-agarose gels, separations based on differences in hydrophobicity, free from interferences from charge and exclusion effects, have been made possible.

The classical explanation of the interaction of non-polar moieties in aqueous solution, as put forward by Frank and Evans ${ }^{1}$, Kauzmann $^{2}$ and others, is that of an essentially entropy-driven hydrophobic interaction. In this view, the interaction between the non-polar moiety of the solute and that of the chromatographic support is mainly the result of the decrease in order when water molecules of the relatively ordered hydration structures (the so-called 'icebergs') surrounding the non-polar groups are released to the less-ordered bulk water. This gives rise to an entropy increase that is supposed to outweigh the accompanying enthalpy change: $\Delta H \ll$ $T \Delta S$. A small value of the enthalpy change is conceived, as the energy needed for the disruption of hydrogen bonds in the 'iceberg' structure is of the same order of magnitude as the energy released in the formation of new hydrogen bonds between water molecules refilling the cage left by the non-polar moiety.

In the hydrophobic interaction chromatography of proteins, adsorption is gen- 
erally obtained by using high salt concentrations in the aqueous adsorption buffer and desorption is brought about either by decreasing the salt concentration in the elution buffer (or by replacing the salt by a 'chaotropic' one) or by adding a less polar cosolvent to the eluent. However, these changes, apart from influencing the hydrophobic interaction, might also affect the intrinsic structural properties of the proteins and, perhaps, of the adsorbent. Therefore, it is difficult to interpret the results of protein chromatography in terms of hydrophobic interactions per se. Thus, to the authors' knowledge, only one paper ${ }^{3}$ has been published in which the relation $\Delta H \ll \mathrm{T} \Delta S$ was shown to prevail for protein adsorption from aqueous solution to (charged) alkyl-agarose.

In this paper we present results of chromatographic experiments with homologous aliphatic monoalcohols and -carboxylic acids on octyl-Sepharose CL-4B. The experiments were performed at several temperatures between 4 and $40^{\circ} \mathrm{C}$ and, for the alcohols, at widely different $\mathrm{pH}$ values, enabling us to determine separately the influence of $\mathrm{pH}$ and the nature of the polar head groups on the thermodynamics of the interaction of the hydrocarbon tail with octyl groups on the chromatographic support.

Whereas the use of these small test compounds circumvents interpretation difficulties as their structure is invariable, it should be emphasized that the interaction of proteins with the chromatographic adsorbent is much more complicated than that of our simple test compounds. For example, in the interaction of a glutamic acid side-chain with octyl-agarose, the terminal carboxylic group almost certainly has to leave the aqueous eluent, whereas butyric acid (one of our test compounds) is in principle capable of hydrophobic interactions whilst keeping its polar head in the eluent. One should realize this if one wishes to extend the conclusions arrived at in this paper to the hydrophobic interaction chromatography of proteins.

\section{THEORETICAL}

The retention on octyl-Sepharose of small amphiphilic compounds with a relatively large non-polar group can be expected to result mainly from hydrophobic interactions. However, other interactions could also play a role. First, electrostatic interactions could occur between residual charged groups on the matrix and charged amphiphiles; for the uncharged test compounds studied in this paper such interactions are non-existent. Second, hydrogen bonds could be formed between the head groups of our test compounds and certain functional groups on the agarose matrix, e.g., between $\mathrm{OH}$ or $\mathrm{COOH}$ head groups and agarose hydroxyls or agarose ether oxygens. The magnitude of this type of interaction can be established experimentally (and its contribution to the retention on octyl-Sepharose subsequently corrected for) by measuring the chromatographic retention on unsubstituted Sepharose under identical conditions.

Such a correction is, of course, not adequate if hydrophobic and hydrogen bonding interactions are cooperative. This also holds for the contribution due to hydrogen bonding of the head groups of our test compounds with hydroxyl and ether oxygen in the spacer arm connecting the octyl group to the agarose matrix. This means that the results on individual test compounds need careful interpretation. However, if we compare the results obtained for members of a homologous series, 
i.e., focus on the interpretation of methylene increment values, the above effects can be expected to cancel.

The most appropriate model for the retention of small amphiphilic compounds on octyl-agarose depends on the density of octyl groups on the gel matrix. If the octyl groups are far apart (i.e., at an average distance greater than the length of the alkyl chain of the solute) it is evident that the retention of the solute should be described as a result of a bimolecular association of the solute with single octyl groups on the gel. A correction should then be applied for retention caused by possible interaction of the solute with the agarose constituent of the matrix. (Interaction of small amphiphiles, e.g., aliphatic monoalcohols, with highly cross-linked Sephadex gels is a well documented phenomenon ${ }^{4}$.) If, on the other hand, the octyl group density is high, such a description is no longer adequate, as the solute can interact simultaneously with more than one octyl group. At extremely high octyl group densities it is even conceivable that the agarose chains of the matrix will be fully covered by an octyl layer, preventing the solute from interacting with agarose. In such an extreme situation, the retention of the solute can be described as a result of its 'partition' between the mobile phase and the octyl layer on the gel. (Still another picture of the retention mechanism is adsorption of the alkyl chain of the solute on an octyl layer surrounding the agarose matrix. Interpretation in terms of this mechanism is hampered, however, by the lack of information on the octyl surface area.)

Unfortunately, the octyl group density on octyl-Sepharose CL-4B is not known with certainty. From the proposed double helix structure of agarose ${ }^{5}$ and the known octyl content of the gel ${ }^{6}$ (about 0.2 mole of octyl per mole of galactose) a mean octyl group density on an agarose double helix of $5 \cdot 10^{-3} \AA^{-2}$ can be calculated ${ }^{7}$. However, in Sepharose 4B, the parent matrix of octyl-Sepharose CL-4B, several agarose double helices are aggregated into fibres. This probably also holds for octyl-Sepharose CL-4B, as neither cross-linking ${ }^{8}$ nor the introduction of octyl groups ${ }^{9}$ seems to alter the permeability of the gel substantially. Obviously, such an aggregation would lead to a greater octyl group density than that indicated above. Unfortunately, the degree of aggregation is uncertain. On the one hand it was estimated ${ }^{10}$ from electron microscopy of Sepharose 4B to range from one to several hundred double helices per fibre; on the other, application of the treatment of Laurent and Killander ${ }^{11}$ to the retention data of Ficoll fractions on $4 \%$ agarose yielded ${ }^{12}$ a mean fibre radius of $25 \AA$, corresponding to an aggregation of about ten double helices per fibre. In a recent electron microscopy study ${ }^{13}$ the degree of aggregation was estimated to be 10-30 double helices per fibre. Based on a mean value of 20 , about a 4.5 times higher mean octyl group density (i.e., $23 \cdot 10^{-3} \AA^{-2}$ ) would be expected for octylSepharose CL-4B, corresponding to a mean distance of the points of attachment to the matrix of about $7 \AA$. This distance must be compared with the length of the alkyl groups of the amphiphiles used in this study, viz., 2.5-8.5 $\AA$.

Hence the available information on the octyl group density does not clearly point to which retention model should be used. However, experimental evidence, i.e., (i) retention as a function of the octyl group density and (ii) the value of the $\mathrm{CH}_{2}$ increment of the standard free energy of sorption, demonstrates that a simple bimolecular association does not occur on octyl-Sepharose CL-4B (see Discussion). We therefore used a partition model for the description of the retention data. The only complication with this model is that the weight of the octyl layer on the gel is 
known, but not its density and hence not its volume. This makes it necessary to use molalities as concentration units.

The partition of a solute $X$ between the aqueous mobile phase $M$ and the stationary phase $\mathrm{S}$ (an octyl layer surrounding the agarose fibres) is described by the partition constant $\boldsymbol{K}_{\boldsymbol{m}}$ :

$$
K_{m}=\frac{\left(m_{\mathrm{X}}\right)_{\mathrm{S}}}{\left(m_{\mathrm{X}}\right)_{\mathrm{M}}}
$$

where $m_{\mathrm{X}}$ represents the molality of $\mathrm{X}$. written as

The elution volume $V_{\mathrm{e}}$ of the solute $\mathrm{X}$ on a column (bed volume $V_{\text {bed }}$ ) can be

$$
V_{\mathrm{e}}=V_{\mathrm{M}}\left(1+K_{m} \cdot \frac{W_{\mathrm{s}}}{W_{\mathrm{M}}}\right)
$$

where $V_{\mathrm{M}}$ is the volume of the mobile phase in the column and $W_{\mathrm{S}}$ and $W_{\mathrm{M}}$ represent the weight of stationary and mobile phase, respectively. As $W_{M}=\rho V_{M}$, where $\rho$ is the specific gravity of the mobile phase, eqn. 2 can be rearranged to

$$
\frac{K_{m}}{\rho}=\frac{V_{\mathrm{e}}-V_{\mathrm{M}}}{W_{\mathrm{S}}}
$$

$V_{M}$ can be evaluated if the specific bed weight, $\beta_{\text {os, }}$ of octyl-Sepharose CL-4B (milligrams of matrix material per millilitre of gel bed) and the density, $\rho_{\mathrm{os}}$, of the gel are known:

$$
V_{M}=V_{\text {bed }}\left(1-10^{-3} \cdot \frac{\beta_{\text {os }}}{\rho_{\text {os }}}\right)
$$

$W_{\mathbf{S}}$ is taken as the weight of octyl groups plus spacer arms through which they are attached to the agarose chains:

$$
W_{\mathrm{S}}=\frac{2 p M_{\mathrm{o}}}{M_{\mathrm{ru}}+2 p M_{\mathrm{o}}} \cdot V_{\mathrm{bed}} \cdot 10^{-3} \beta_{\mathrm{os}}
$$

where $p$ denotes the octyl concentration (moles of octyl per mole of galactose), $\boldsymbol{M}_{\text {。 }}$ represents the molecular weight of the octyl group + spacer $\operatorname{arm}\left(M_{0}=186\right)$ and $M_{\mathrm{ru}}$ that of the galactose-anhydrogalactose repeating unit in agarose $\left(M_{\mathrm{ru}}=306\right)$. Note that the weight of the cross-links has been neglected in eqn. 5 .

In deriving eqn. 3 , it is tacitly assumed that the solute $\mathbf{X}$ is not involved in association processes, e.g., micellization, in the mobile phase. The following arguments can be raised in favour of this assumption.

(i) The overall octyl concentration in the gel bed is about $400 \mathrm{mM}$, and that of the test compounds in the eluent is at maximum equal to the sample concentration, which ranged between 8 and $17 \mathrm{mM}$ (see Experimental). It is difficult to imagine why, 
under these circumstances, a solute molecule would 'prefer' self-association to association with octyl groups of the gel.

(ii) The elution peaks were generally symmetrical (see Experimental), which means that the retention is independent of the solute concentration. This fact cannot be reconciled with monomer-dimer (or micellar) equilibria in the mobile phase.

(iii) For the highest members of a homologous series the elution peaks were slightly asymmetric. If this were due to self-association in the mobile phase, i.e., to a process reversed to the chromatographic retention, one would expect the free energy change per $\mathrm{CH}_{2}$ group to diminish for these higher members. Such an effect is not observed, however (see Fig. 2).

\section{EXPERIMENTAL}

Octyl-Sepharose CL-4B (Pharmacia, Uppsala, Sweden) was washed several times with the eluent and, after deaeration of the suspension, packed in a thermostatically controlled column (K16/70, Pharmacia) to a bed height of about $60 \mathrm{~cm}$ (bed volume about $120 \mathrm{ml}$ ) at an eluent flow-rate of about $15 \mathrm{ml} \mathrm{h}^{-1}$. The column was equipped with a sample valve (LV4, Pharmacia), a flow adaptor (A16, Pharmacia), a peristaltic pump (Minipuls 2; Gilson, Villiers-le-Bel, France) and a 70- $\mu 1$ UV monitor (Uvicord S; LKB, Bromma, Sweden) or a $10-\mu l$ refractive index (RI) detector (R-403; Waters Assoc., Milford, MA, U.S.A.).

Sample solutions were prepared by dissolving the test compounds in the eluent to a concentration of about $1 \mu \mathrm{ml}^{-1}$ or $1 \mathrm{mg} \mathrm{ml}^{-1}$. When (with some of the higher homologues) these concentrations could not be obtained, saturated solutions of the test compounds were used.

Aliquots of 1-2 ml were applied to the column and eluted at a flow-rate of about $15 \mathrm{ml} \mathrm{h}^{-1}$. The purity of the test compounds (of various origins) was always $\geqslant 98 \%$; they were used without further purification. Analytical-reagent grade compounds (Baker, Deventer, The Netherlands) and doubly distilled water were used to prepare the eluents. The eluent composition was $25 \mathrm{mM}$ sodium phosphate, $\mathrm{pH} 3.52$ (alcohols and carboxylic acids) or pH 7.10 (alcohols). At pH 3.52 the carboxylic acids are essentially uncharged. Chromatograms were obtained by recording the UV absorbance at $206 \mathrm{~nm}$ (carboxylic acids) or the RI signal (alcohols). Flow-rates were determined gravimetrically.

A few experiments with both series of test compounds were performed at different eluent flow-rates $\left(10\right.$ and $\left.30 \mathrm{ml} \mathrm{h}^{-1}\right)$. $K$ values calculated from these experiments with eqn. 3 , taking into account the slightly different specific bed weights, were identical within experimental error.

Some experiments were performed with hexanol at different solute concentrations $\left(0.2\right.$ and $\left.0.5 \mathrm{mg} \mathrm{ml}^{-1}\right)$; the elution volumes were identical with that at $1 \mathrm{mg}$ $\mathrm{ml}^{-1}$.

The elution peaks were generally symmetrical; the HETP values ranged from 0.03 to $0.06 \mathrm{~cm}$. Some minor tailing was observed, however, with the highest members of a homologous series.

After completion of a series of measurements with a given eluent at a given temperature, about $10 \mathrm{ml}$ of the gel bed on top of the column were slurried into the supernatant eluent and most of it was withdrawn. Subsequently the remaining slurry 
was repacked at the same flow-rate, restoring a flat bed surface. The decrease in bed volume $(\Delta V)$ was measured. The gel slurry was transferred to a weighed glass filter, thoroughly washed with distilled water and ethanol-water mixtures of increasing ethanol content and dried at $90^{\circ} \mathrm{C}$ to constant weight $(W)$. From these data the specific bed weight $\beta_{\text {os }}$ (milligrams of octyl-Sepharose per millilitre of gel bed), pertaining to a given eluent and temperature, was calculated as $\beta_{\text {os }}=W / \Delta V$.

Octyl-agarose of varying degrees of octyl substitution was prepared from Sepharose CL-4B using the method of Hjertén et al. ${ }^{14}$. Its octyl concentration was determined by NMR spectroscopy ${ }^{15}$. Some of the test compounds were chromatographed on this material (at slightly different buffer concentrations and $\mathrm{pH}$ values).

\section{RESULTS}

In Fig. $1 K_{m}$ values, calculated according to eqns. 3-5, are given for the retention of hexanoic and heptanoic acids on octyl-agaroses of varying degree of octyl substitution.

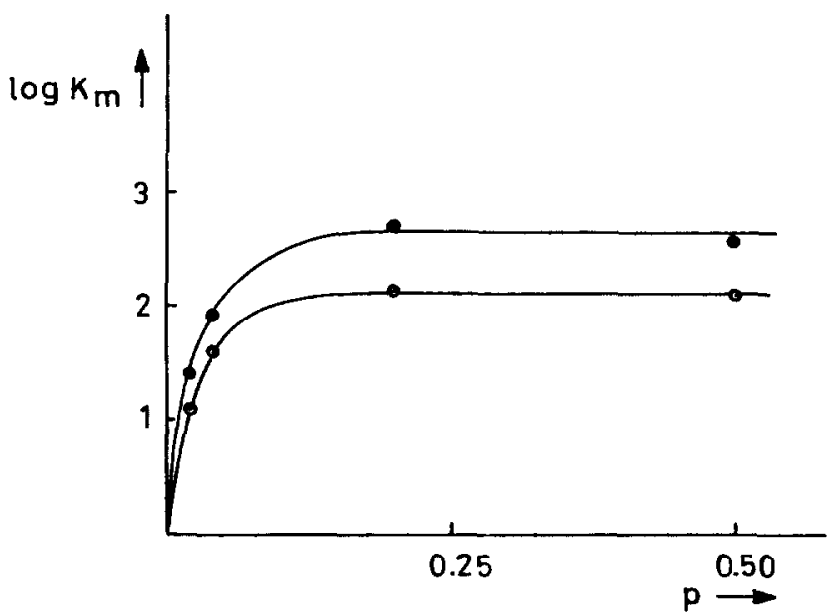

Fig. 1. $K_{m}$ values at $25^{\circ} \mathrm{C}$ for hexanoic $(O)$ and heptanoic acid $(O)$ versus the degree of octyl substitution in octyl-agarose. Eluent: $5 \mathrm{mM}$ phosphate, $\mathrm{pH} 2.7$.

In Table I the elution volumes (corrected for dead volume and normalized to a bed volume of $100 \mathrm{ml}$ ) of the test compounds on octyl-Sepharose CL-4B and Sepharose CL-4B are given at different $\mathrm{pH}$ values of the eluent and at different temperatures. From the speed stability of the peristaltic pump and the time interval of eluent weighings relative to the retention times found, and also from the differences between occasional duplicates, we estimate the precision of these normalized values to be about $0.2 \%$.

In Table II the specific bed weights of octyl-Sepharose CL-4B and Sepharose $\mathrm{CL}-4 \mathrm{~B}$ are given at the same $\mathrm{pH}$ values and temperatures. The precision of these values is about $1 \%$.

The data in Tables I and II were used to calculate $K_{m}$ values using eqns. 3-5. 


\section{TABLE I}

ELUTION VOLUMES (ml) OF THE TEST COMPOUNDS ON 100-ml BEDS OF OCTYL-SEPHAROSE CL-4B AND SEPHAROSE CL-4B

\begin{tabular}{|c|c|c|c|c|c|c|c|c|c|}
\hline \multirow[t]{2}{*}{ Eluent } & \multirow{2}{*}{$\begin{array}{l}\text { Test } \\
\text { compound }\end{array}$} & \multirow[t]{2}{*}{$n$} & \multicolumn{6}{|c|}{ Octyl-Sepharase } & \multirow{2}{*}{$\begin{array}{l}\text { Sepharose } \\
25^{\circ} \mathrm{C}^{\star}\end{array}$} \\
\hline & & & $4^{\circ} \mathrm{C}$ & $10^{\circ} \mathrm{C}$ & $17.5^{\circ} \mathrm{C}$ & $25^{\circ} \mathrm{C}$ & $32.5^{\circ} \mathrm{C}$ & $40^{\circ} \mathrm{C}$ & \\
\hline \multirow{5}{*}{$\begin{array}{l}25 \mathrm{~m} M \\
\text { sodium } \\
\text { phosphate } \\
\text { (pH 3.52) }\end{array}$} & \multirow{5}{*}{$C_{n} \mathrm{H}_{2 n+1} \mathrm{COOH}$} & 2 & 99.1 & 99.7 & 99.6 & 99.2 & 99.5 & 99.2 & 98.2 \\
\hline & & 3 & 102.5 & 103.5 & 101.9 & 101.7 & 101.2 & 101.3 & 98.3 \\
\hline & & 4 & 110.9 & 111.6 & 111.2 & 110.0 & 111.0 & 109.7 & 98.5 \\
\hline & & 5 & 143.2 & 144.3 & 142.7 & 140.8 & 139.1 & 135.6 & 98.4 \\
\hline & & 6 & 261.7 & 264.3 & 259.0 & 253.8 & 241.6 & 228.0 & 99.4 \\
\hline \multirow{5}{*}{$\begin{array}{l}25 \mathrm{~m} M \\
\text { sodium } \\
\text { phosphate } \\
\text { (pH 3.52) }\end{array}$} & \multirow{5}{*}{$\mathrm{C}_{n} \mathrm{H}_{2 n+1} \mathrm{OH}$} & 3 & 98.6 & 99.0 & 98.8 & 98.8 & 99.7 & 98.8 & 98.1 \\
\hline & & 4 & 99.9 & 100.8 & 100.5 & 100.7 & 100.7 & 101.6 & 98.1 \\
\hline & & 5 & 105.0 & 106.3 & 106.6 & 108.0 & 108.3 & 108.0 & 98.5 \\
\hline & & 6 & 124.6 & 127.1 & 129.8 & 133.3 & 134.1 & 133.3 & 98.8 \\
\hline & & 7 & 194.3 & 206.5 & 217.1 & 224.9 & 228.8 & 219.0 & 99.0 \\
\hline \multirow{5}{*}{$\begin{array}{l}25 \mathrm{mM} \\
\text { sodium } \\
\text { phosphate } \\
\text { (pH 7.10) }\end{array}$} & \multirow{5}{*}{$\mathrm{C}_{n} \mathrm{H}_{2 n+1} \mathrm{OH}$} & 3 & 98.5 & 98.6 & 98.9 & 98.8 & 98.9 & 98.6 & 97.7 \\
\hline & & 4 & 100.8 & 101.3 & 101.1 & 102.3 & 102.2 & 102.7 & 97.8 \\
\hline & & 5 & 110.6 & 111.3 & 112.8 & 113.9 & 115.1 & 115.8 & 98.0 \\
\hline & & 6 & 143.3 & 147.9 & 153.9 & 156.4 & 160.7 & 161.7 & 97.9 \\
\hline & & 7 & 270.0 & 288.2 & 306.1 & 316.1 & 328.8 & 327.8 & 98.1 \\
\hline
\end{tabular}

* Elution volumes on Sepharose CL-4B were independent of temperature (within experimental error).

TABLE II

SPECIFIC BED WEIGHT (mg/ml) OF OCTYL-SEPHAROSE CL-4B

\begin{tabular}{llllllll}
\hline Eluent & \multicolumn{7}{c}{ Temperature $\left({ }^{\circ} \mathrm{C}\right)$} \\
\cline { 2 - 7 } & 4 & 10 & 17.5 & 25 & 32.5 & 40 \\
\hline $25 \mathrm{~m} M$ sodium phosphate (pH 3.52) & 35.1 & 34.3 & 33.1 & 31.7 & 30.0 & 28.1 \\
$25 \mathrm{~m} M$ sodium phosphate (pH 7.10) & 37.3 & 37.1 & 36.3 & 36.3 & 35.4 & 33.4 \\
\hline
\end{tabular}

In this calculation we assumed $\rho_{\text {os }}=1.6$ (approximately the density of a related polysaccharide, Sephadex G-200). The octyl concentrations, $p$, for the batches of octyl-Sepharose CL-4B used were given by the manufacturer.

Values of the (partial molal) standard free energy change for the partition process $\left(\Delta G^{\circ}\right)$ were determined from the equation

$$
\Delta G^{\mathrm{o}}=-R T \ln K_{m}
$$

In Fig. $2 \Delta G^{\circ}$ values at $25^{\circ} \mathrm{C}$ are plotted against the chain length, $n$, for the three series of measurements.

Fig. 3 shows a typical Van 't Hoff plot $\left(\Delta G^{\circ} / T\right.$ versus $\left.1 / T\right)$ for one of the series, the alcohols at $\mathrm{pH} 7.10$. 


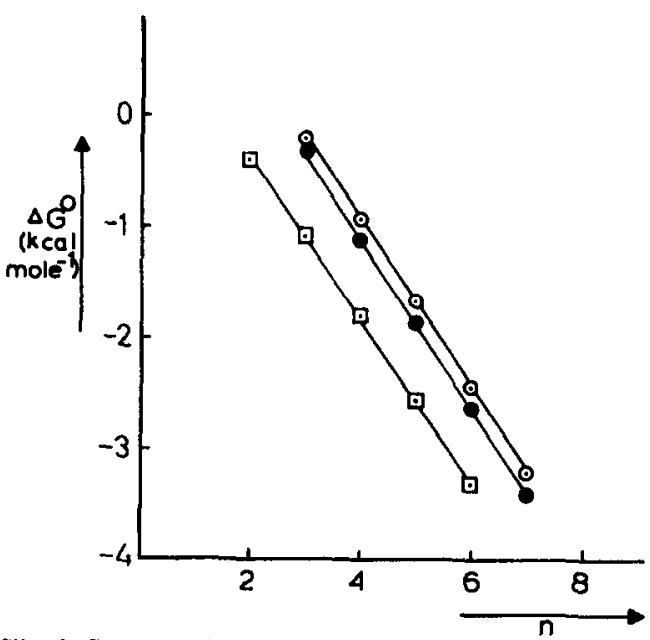

Fig. 2. Standard free energy at $25^{\circ} \mathrm{C}$ versus chain length for carboxylic acids at pH 3.52 ( $\square$ ) and alcohols at $\mathrm{pH} 3.52(\mathrm{O})$ and $\mathrm{pH} 7.10(\mathrm{O})$.

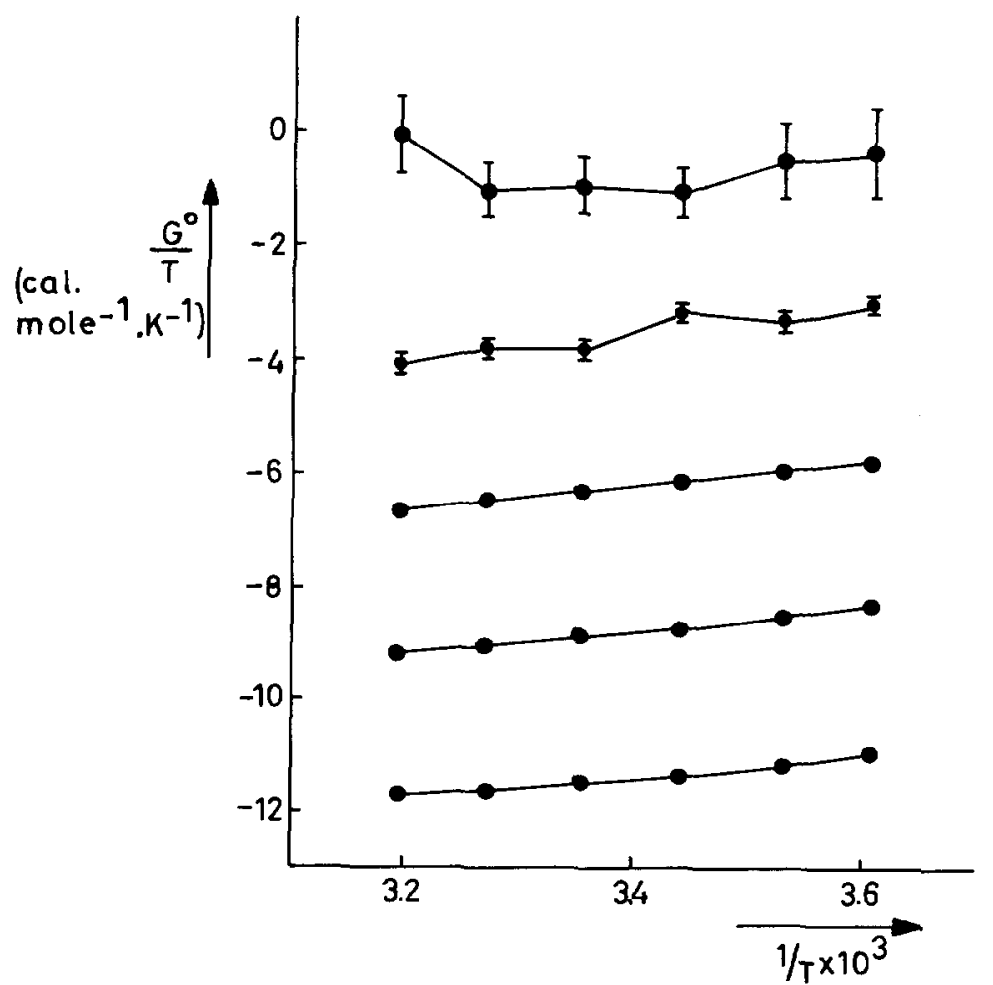

Fig. 3. Van 't Hoff plot for alcohois in $25 \mathrm{mM}$ phosphate buffer at pH 7.10 . 
Values of the standard thermodynamic quantities $\Delta C_{p}^{\circ}, \Delta H^{\circ}$ and $\Delta S^{\circ}$ at $25^{\circ} \mathrm{C}$ were calculated with eqn. 7 . In this equation, $\Delta C_{p}{ }^{\circ}$ is assumed ${ }^{16}$ to be independent of temperature and $\theta=298.1^{\circ} \mathrm{K}$.

$$
Y \equiv \frac{\Delta G^{\circ}}{T}-\Delta C_{p}^{\circ}\left(1-\frac{\theta}{T}-\ln \frac{T}{\theta}\right)=-\Delta S_{\theta}^{\circ}+\Delta H_{\theta}^{\circ} \cdot \frac{1}{T}
$$

For this purpose, values of $Y$ were calculated with different pre-set $\Delta C_{p}{ }^{\circ}$ values. Sets of $Y$ versus $1 / T$ data were analysed with the least-squares treatment for linear regression. The values of $\Delta C_{p}{ }^{\circ}$ that gave the best fit to the linear equation $Y=a+b\left(\frac{1}{T}\right)$ were retained. The slope $b$ and the intercept $a$ of this line were equated to $\Delta H_{\theta}{ }^{\circ}$ and $\Delta S_{\theta}{ }^{\circ}$, respectively. The results are given in Table III and Fig. 4. Note that this treatment is unable to extract thermodynamic data from the results for the first members of each series in Table I, as a result of the large experimental errors involved.

\section{TABLE III}

THERMODYNAMIC DATA FOR BINDING TO OCTYL-SEPHAROSE CL-4B $\Delta C_{p}{ }^{\circ}, \Delta S^{0}$ and $s_{y}$ in cal ${ }^{\circ} \mathrm{K}^{-1}$ mole $^{-1} ; \Delta H^{0}$ in cal mole ${ }^{-1}$

\begin{tabular}{lllllllll}
\hline Eluent & $p H$ & Test compound & $n$ & \multicolumn{1}{l}{$\Delta C_{p}^{\circ}$} & \multicolumn{1}{l}{$\Delta H^{\circ}$} & \multicolumn{1}{l}{$\Delta S^{\circ}$} & \multicolumn{1}{l}{$s_{y}$} \\
\hline $\begin{array}{c}25 \mathrm{~m} M \text { sodium } \\
\text { phosphate }\end{array}$ & 3.52 & $\mathrm{C}_{n} \mathrm{H}_{2 n+1} \mathrm{COOH}$ & 3 & 35 & $-1589 \pm 657$ & $-1.6 \pm 2.2$ & 0.23 \\
& & & 4 & -13 & $291 \pm 265$ & $7.2 \pm 0.9$ & 0.09 \\
& & & 5 & -39 & $-65 \pm 61$ & $8.4 \pm 0.2$ & 0.02 \\
& & & 6 & -61 & $-330 \pm 31$ & $10.0 \pm 0.1$ & 0.01 \\
$25 \mathrm{~m} M$ sodium & 3.52 & $\mathrm{C}_{n} \mathrm{H}_{2 n+1} \mathrm{OH}$ & 4 & 48 & $2569 \pm 764$ & $11.7 \pm 2.6$ & 0.27 \\
phosphate & & & 5 & -83 & $2205 \pm 186$ & $13.0 \pm 0.6$ & 0.07 \\
& & & 6 & -65 & $2182 \pm 91$ & $15.5 \pm 0.3$ & 0.03 \\
& & & 7 & -113 & $1766 \pm 85$ & $16.7 \pm 0.3$ & 0.03 \\
25 mM sodium & 7.10 & $\mathrm{C}_{n} \mathrm{H}_{2 n+1} \mathrm{OH}$ & 4 & 32 & $2592 \pm 482$ & $12.3 \pm 1.6$ & 0.17 \\
phosphate & & & 5 & 11 & $2127 \pm 33$ & $13.4 \pm 0.1$ & 0.01 \\
& & & 6 & -30 & $1949 \pm 77$ & $15.4 \pm 0.3$ & 0.03 \\
& & & 7 & -40 & $1691 \pm 55$ & $17.2 \pm 0.2$ & 0.02 \\
\hline
\end{tabular}

From the precision of the data in Tables I and II, the expected error in $\Delta G^{\circ} / T$ can be estimated. In Fig. 5 this error is shown in a logarithmic plot as a function of the elution volume $V_{\mathrm{e}}$. It can be seen that for $V_{\mathrm{e}}>150 \mathrm{ml}$ the error is essentially constant as it is governed by the precision of the specific bed weight data (Table II). For $V_{\mathrm{e}}<120 \mathrm{ml}$ it increases steeply with decreasing $V_{\mathrm{e}}$ as the difference $V_{\mathrm{e}}-V_{\mathrm{M}}$ (eqn. 3) becomes increasingly small.

For comparison, the error $s_{y}$ in a single $Y$-value (Table III), as found in the least-squares treatment, is also indicated in Fig. 5, for each test compound. It can be inferred that in general the consistency of the data at different temperatures is satisfactory: only in a few cases is $s_{y}$ larger than expected from measurements at a single temperature. 

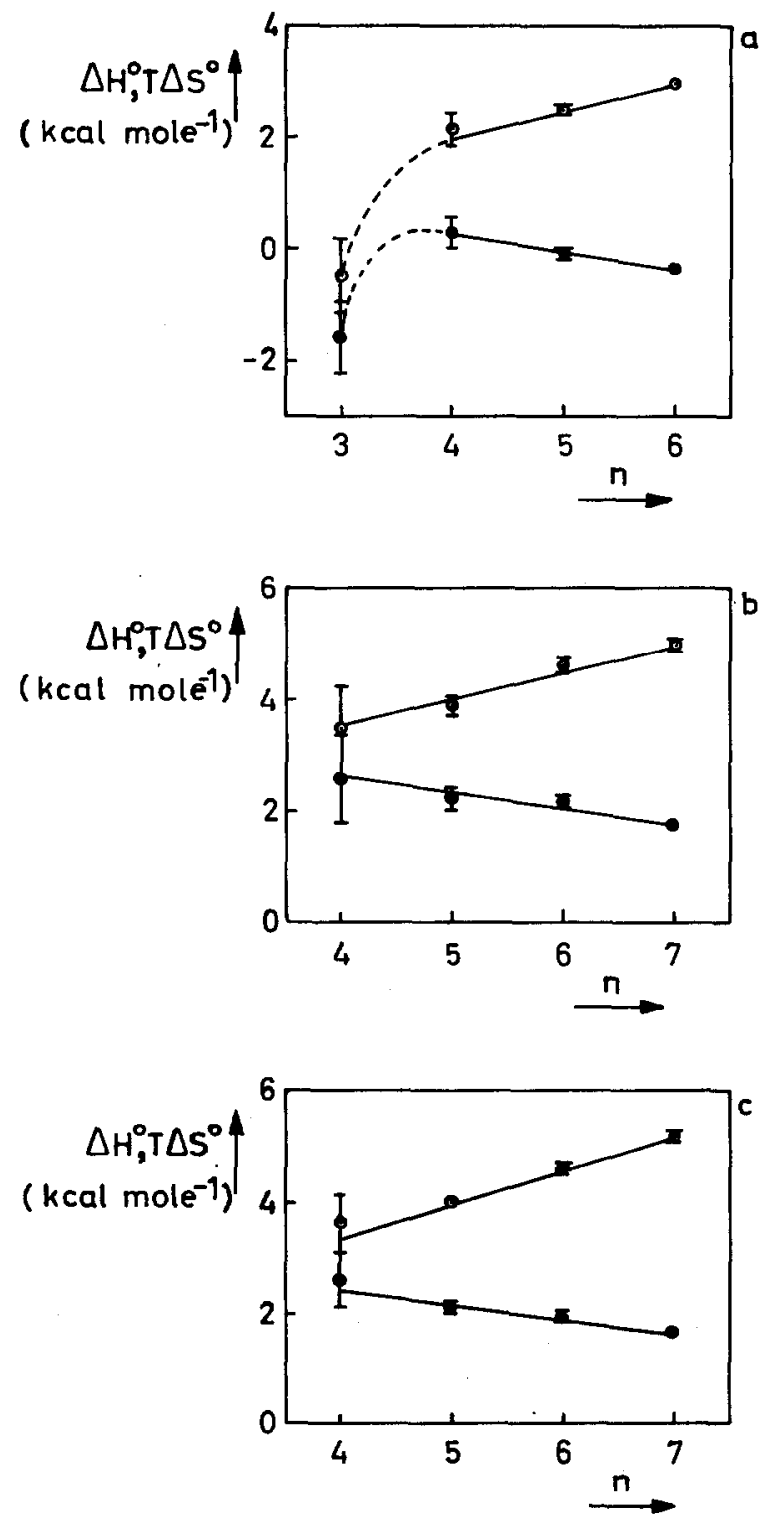

Fig. 4. Values of $\Delta H^{\circ}(\Theta)$ and $T \Delta S^{\circ}(O)$ at $25^{\circ} \mathrm{C}$ versus chain length. (a) Carboxylic acids (pH 3.52); (b) alcohols (pH 3.52); (c) alcohols (pH 7.10).

\section{DISCUSSION AND CONCLUSIONS}

\section{Retention on unsubstituted Sepharose}

The results in the last column of Table I give rise to the following remarks. From the specific bed weight of Sepharose CL-4B (Table II) and an assumed density of the polymer of $1.6 \mathrm{~g} \mathrm{ml}^{-1}$, a total volume of mobile and stationary phase in a 


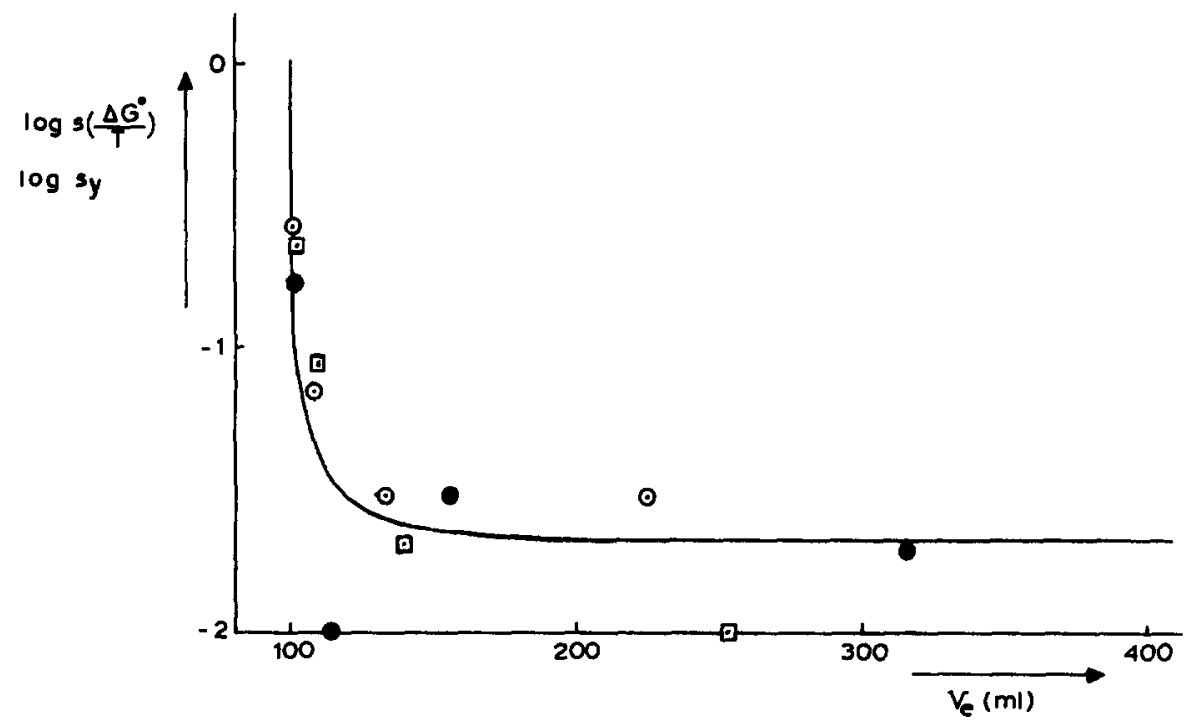

Fig. 5. Calculated standard error in $\Delta G^{\circ} / T(\longrightarrow$ ) and experimental standard errors in $Y$ versus elution volume on a $100-\mathrm{ml}$ octyl-Sepharose column at $25^{\circ} \mathrm{C}$. Notation of experimental data as in Fig. 2.

$100-\mathrm{ml}$ bed of 97.9 and $97.8 \mathrm{ml}$ can be estimated in $25 \mathrm{mM}$ buffer at pH 3.52 and 7.10 , respectively.

At pH 3.52, the elution volumes of alcohols and carboxylic acids are greater than $97.9 \mathrm{ml}$ and increase with increasing chain length. This indicates a small but measurable interaction of the non-polar part of the amphiphiles with the polysaccharide. Such an interaction, but more pronounced, was also found on highly crosslinked Sephadex by Haglund and Marsden ${ }^{4}$.

It is not clear why the same effect is not found with the alcohol series at $\mathbf{p H}$ 7.10 , especially as the interaction of alcohols with octyl-substituted Sepharose is stronger at $\mathrm{pH} 7.10$ than at $\mathrm{pH} 3.52$. A possible reason could be that at $\mathrm{pH} 7.10$ the matrix contains some residual charged carboxylate groups, preventing hydrophobic interaction of the alcohols with the matrix (but not with octyl groups on the octylsubstituted matrix).

For all but the lowest members of each homologous series the retention on unsubstituted Sepharose is small compared with that on octyl-Sepharose. Therefore, elution volumes on octyl-Sepharose were not corrected for retention on unsubstituted Sepharose; it can be shown that this introduces no significant changes in the thermodynamic data to be discussed in the following sections.

\section{Retention on octyl-Sepharose}

Influence of the octyl concentration of the gel

Earlier literature reports on the retardation of small model compounds on octyl-agarose seem to disagree. Thus, Hjertén ${ }^{17}$ stated that such compounds are not retarded, whereas we found ${ }^{18}$ significant retardation of tripeptides such as trileucine. However, the discrepancy might result from the fact that we used octyl-Sepharose CL-4B with a high octyl content (about 200 mmole/mole galactose) whereas Hjerten 
used alkyl-agaroses with considerably lower octyl contents (less than $125 \mathrm{mmole} / \mathrm{mole}$ galactose). Therefore, we measured the retentions of hexanoic and heptanoic acids on octyl-agaroses with different octyl concentrations. Fig. 1, where $\log K_{m}$ values are plotted against the degree of octyl substitution, $p$, clearly indicates that at $p \approx 0.20$ (the degree of substitution of octyl-Sepharose CL-4B) a simple bimolecular association mechanism is not operative and provides an argument for the treatment of our experimental data in terms of a partition model (see Theoretical).

\section{Influence of $p H$}

For a purely hydrophobic interaction of a non-protolytic solute the $\mathrm{pH}$ is not expected to exert any effect. Indeed, it can be seen in Fig. 2 that a change in $\mathrm{pH}$ from 3.5 to 7.1 has only a minor effect on the interaction of alcohols with octyl groups on the gel. The slight increase in the strength of interaction with increase in $\mathrm{pH}$ could be due to the difference in the compositions of the phosphate buffers used, the salting-out effect of $\mathrm{HPO}_{4}{ }^{2-}$ ions being greater than that of $\mathrm{H}_{2} \mathrm{PO}_{4}{ }^{-}$ions.

The interaction of proteins with octyl-agarose is often found to weaken at high $\mathrm{pH}^{6,19}$. In the light of the above results, this cannot be due to a weakening of the hydrophobic interaction per se. Other effects of $\mathrm{pH}$, e.g., a pH-induced conformation change of the protein, must be evoked to explain such results.

\section{Influence of the nature of the head group}

It can be seen in Fig. 2 that for an equal length of the alkyl chain R, the interaction with octyl groups on the gel is stronger for a carboxylic acid $\mathrm{RCOOH}$ than for an alcohol ROH.

In a paper on solvophobic interactions, Horváth et al. ${ }^{20}$ derived a theoretical expression for the free energy change on transfer of an amphiphile from solution to the neighbourhood of hydrocarbonaceous ligands of bonded phases. This expression fails to explain the difference we find for the free energy change for alcohols and carboxylic acids of equal chain length. In this instance, the solvophobic theory predicts a difference originating mainly from the electrostatic contribution to the free energy change. This contribution, for an uncharged solute, is governed by its static dipole moment. However, alcohols and carboxylic acids have nearly the same values (1.65 and 1.75 Debye, respectively).

The difference might be explained by assuming that the hydrophilic hydration of an $\mathrm{OH}$ group is stronger than that of a $\mathrm{COOH}$ group. The hydrophilic hydration sphere of these head groups possibly extends over the nearest $\mathrm{CH}_{2}$ groups of the alkyl chain, preventing hydrophobic interaction of that part of the chain with octyl groups of the gel, the effect being stronger for an alcohol than for a carboxylic acid.

In Fig. 6 our $\Delta G^{\circ}$ values are plotted against $n$ for the transfer of alcohols (pH 7.10) and carboxylic acids ( $\mathrm{pH} 3.52$ ) from water to octyl-agarose together with literature data (recalculated to convert them to a common molality basis) for the transfer from water to heptane, octane, octanol and the pure liquid. It can be seen that the free energy state of these uncharged solutes in the octyl gel closely resembles that in octanol. In other words, the distribution constants in the system octanol-water are to a great extent indicative of the retention behaviour on octyl-agarose: $K_{m} \approx$ $k_{\text {octanol-water. }}$ (For the retention on alkylsilica from aqueous solution it has been

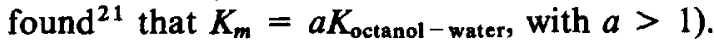



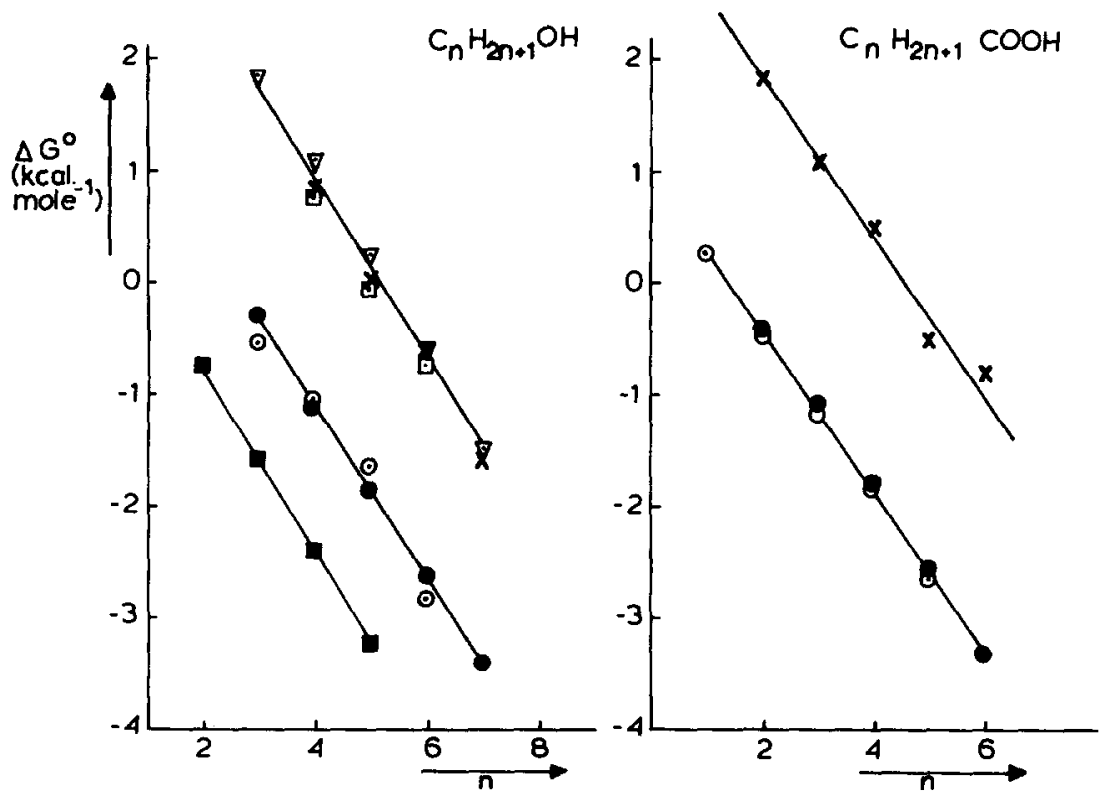

Fig. 6. Standard free energy change for the transfer of alcohols and carboxylic acids from water to octyl agarose ( $\odot$, this work), from water to hexane ( $\times$, ref. 22 ), from water to octane ( $\square$, ref. $23 ; \nabla$, ref. 24$)$, from water to pure liquid ( $\boldsymbol{m}$, ref. 25$)$ and from water to octanol $(O$, ref. 26).

In octanol solution the free energy state of the test compounds is determined by hydrophobic interactions of their alkyl chains with alcohol octyl groups and by hydrogen bonding of the head groups with octanol hydroxyls. The above finding strongly suggests that in chromatography on octyl-Sepharose, in addition to hydrophobic interactions, hydrogen bonding of the head groups also takes place, presumably with hydroxyls of the spacer or of the agarose matrix.

\section{Influence of chain length}

As expected for a mainly hydrophobic interaction, lengthening of the alkyl chain increases the extent of interaction with octyl groups on the gel for each series of measurements (Fig. 2). The fact that the lines in Fig. 2 are straight and nearly parallel is plausible. It indicates that, if sufficiently distant from the polar head group (see Influence of the nature of the head group), each $\mathrm{CH}_{2}$ group of the alkyl chain gives a constant contribution to the free energy change, independent of $\mathrm{pH}$ and the nature of the head group. This is found in many processes in which hydrophobic interactions play a dominant role $^{27}$.

The value of the free energy change for multimolecular association per methylene group, $\Delta \Delta G^{\circ}\left(\mathrm{CH}_{2}\right)$, depends only slightly on the nature of the process studied, as can be seen in the following compilation ${ }^{27}$ (all values in $\mathrm{kcal} \mathrm{mole}^{-1}$ ):

micelle formation from amphiphiles in water

association of amphiphiles with proteins

adsorption of amphiphiles to water-paraffin oil interface

$-0.81$

partition of amphiphiles between organic solvents and water

$-0.83$ dissolution of hydrocarbons in water 
TABLE IV

VALUES OF $\triangle A G^{\circ}\left(\mathrm{CH}_{2}\right)$ FOR RETENTION OF ALCOHOLS AND CARBOXYLIC ACIDS ON ALKYL-SUBSTITUTED AGAROSE AND SILICA

\begin{tabular}{|c|c|c|c|c|c|c|}
\hline $\begin{array}{l}\text { Homologous } \\
\text { series }\end{array}$ & Eluent & $p H$ & $\begin{array}{l}\text { Temp. } \\
\left({ }^{\circ} \mathrm{C}\right)\end{array}$ & $\begin{array}{l}\text { Chromatographic } \\
\text { support }\end{array}$ & $\begin{array}{l}\Delta \Delta g^{0}\left(\mathrm{CH}_{2}\right) \\
\left(\text { kcal mole }^{-1}\right)\end{array}$ & Ref. \\
\hline $\begin{array}{l}\text { Carboxylic acids } \\
\text { Alcohols } \\
\text { Alcohols }\end{array}$ & $\begin{array}{l}25 \mathrm{mM} \text { phosphate } \\
\text { buffer }\end{array}$ & $\begin{array}{l}3.52 \\
3.52 \\
7.10\end{array}$ & 25 & Octyl-agarose & $\begin{array}{l}0.74 \pm 0.02 \\
0.76 \pm 0.02 \\
0.77 \pm 0.01\end{array}$ & This work \\
\hline $\begin{array}{l}\text { Alcohols } \\
\text { Alcohols }\end{array}$ & Water & 7 & 27.5 & $\begin{array}{l}\text { Hexylsilica } \\
\text { Decylsilica }\end{array}$ & $\begin{array}{l}0.75 \\
0.81\end{array}$ & 28 \\
\hline $\begin{array}{l}\text { Several } \\
\text { compounds }\end{array}$ & $\begin{array}{l}100 \mathrm{~m} M \text { phosphate } \\
\text { buffer }\end{array}$ & 2.15 & 25 & $\begin{array}{l}\text { Several } \\
\text { alkylsilicas }\end{array}$ & $0.82 \pm 0.02$ & 29 \\
\hline
\end{tabular}

In Table IV values of $\Delta \Delta G^{\circ}\left(\mathrm{CH}_{2}\right)$ resulting from our measurements are compared with those derived from HPLC measurements on alkylsilicas.

The values in Table IV are all very nearly the same, and nearly equal to those given above. However, in view of the barely differing values of $\Delta \Delta G^{\circ}\left(\mathrm{CH}_{2}\right)$ given above for very different processes, these nearly identical values for retention on alkyl-agarose and alkylsilica cannot be taken as proof of a similar retention mechanism on the two chromatographic supports (there is increasing evidence ${ }^{30,31}$ that the retention on alkylsilica, at least from partly aqueous eluents, should be described in terms of adsorption on an alkyl layer).

Values of $\Delta \Delta G^{\circ}\left(\mathrm{CH}_{2}\right)$ for processes that can only be conceived in terms of bimolecular association, e.g., dimerization of carboxylic acids in water ${ }^{32}$ and ion pair formation from alkylammonium and carboxylate ions in water ${ }^{32}$, are considerably different from the above-mentioned values (about $-0.30 \mathrm{kcal} \mathrm{mole}^{-1}$ ). This supports the conclusion we arrived at under Influence of the octyl concentration of the gel, namely that a bimolecular association mechanism is not operative in hydrophobic interactions of our test compounds with octyl-Sepharose. It implies that the octyl group density on the agarose fibres is, at least locally, fairly high.

Influence of temperature and thermodynamics of the retention process

General survey. Processes in which hydrophobic interactions play an important role are generally characterized by relatively large and negative values of the standard heat capacity change, $\Delta C_{p}{ }^{\circ}$, and by relatively large and positive values of the standard entropy change, $\Delta S^{\circ}$. These effects have been ascribed to the thermally labile hydrophobic hydration structures and to a general decrease in order on interaction, respectively. It can be seen in Table III that most of the $\Delta C_{p}{ }^{\circ}$ data are negative and virtually all of the $\Delta S^{\circ}$ data are positive.

As the contribution of hydrophobic interactions to the retention increases with increasing length of the alkyl chain of the solute, one would expect $\Delta C_{p}{ }^{\circ}$ and $\Delta S^{\circ}$ to become increasingly negative and positive, respectively, with increasing chain length. This is also clearly born out in the results.

In the Introduction, the general rule for hydrophobic interactions, $\Delta H<T \Delta S$, 
was mentioned. In Fig. 4 , where that standard values $\Delta H^{\circ}$ and $T \Delta S^{\circ}$ are plotted against chain length, it can be seen that for the three series this rule is obeyed the better, the longer is the alkyl chain. This is to be expected, as the contribution of hydrophobic interactions increases with increasing chain length.

Heat capacity values. The generally negative values, decreasing with increasing chain length, are in good agreement with the order-disturbance concept of hydrophobic interactions. For the alcohol (pH 7.10) and the carboxylic acid series, the mean contributions of a methylene group to the standard heat capacity change, $\Delta \Delta C_{p}{ }^{\circ}\left(\mathrm{CH}_{2}\right)$, are about -30 and $-25 \mathrm{cal} \mathrm{mole}^{-1}{ }^{\circ} \mathrm{K}^{-1}$, respectively. These values are more negative than the value $\left(-20 \mathrm{cal} \mathrm{mole}{ }^{-1}{ }^{\circ} \mathrm{K}^{-1}\right)$ reported by Konicek and Wadso ${ }^{33}$ for the transfer of a $\mathrm{CH}_{2}$ group from water to pure alcohol and carboxylic acid. However, as can be seen in Fig. 7 , where our $\Delta C_{p}{ }^{\circ}$ values are compared with literature values pertaining to the transfer of these solutes from water to the pure liquids, the discrepancy stems mainly from results with short alkyl chain lengths, which are less accurate.
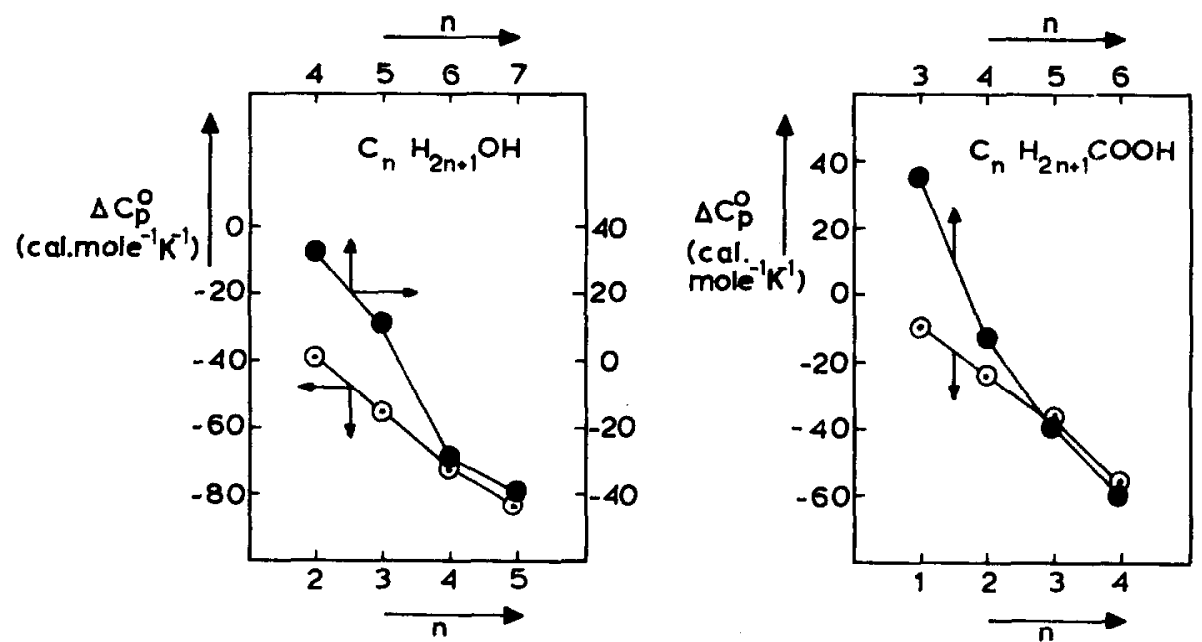

Fig. 7. $\Delta C_{p}{ }^{\circ}\left(\mathrm{CH}_{2}\right)$ versus chain length for the transfer of alcohols and carboxylic acids from water to octyl-agarose ( $O$, this work) and from water to the pure liquids $(O$, refs. 33 and 34$)$.

Enthalpy values. Fig. 4 shows that $\Delta H^{\circ}$ for the alcohols (at $\mathrm{pH} 3.52$ and $\mathrm{pH}$ $7.10)$ is positive, decreasing with increasing chain length. For the carboxylic acids $\Delta H^{\circ}$ also decreases with increasing chain length from slightly positive to slightly negative values. The contributions of a $\mathrm{CH}_{2}$ group to the standard enthalpy change, $\Delta \Delta H^{\circ}\left(\mathrm{CH}_{2}\right)$, are almost identical in the three series for $\mathrm{n} \geqslant 4$, being about $-0.3 \mathrm{kcal}$ mole $^{-1}$. This value is in fair agreement with that pertaining to the transfer of these solutes from water to the pure liquids, as is demonstrated in Fig. 8, where our $\Delta H^{\circ}$ values are compared with literature data, recalculated to convert them to a common molality basis.

About the same contribution of a methylene group was found ${ }^{23,35}$ in the enthalpy of transfer of these solutes from water to $n$-octane $(-0.39$ and $-0.28 \mathrm{kcal}$ mole $^{-1}$ for alcohols and carboxylic acids, respectively) and in the enthalpy of transfer 

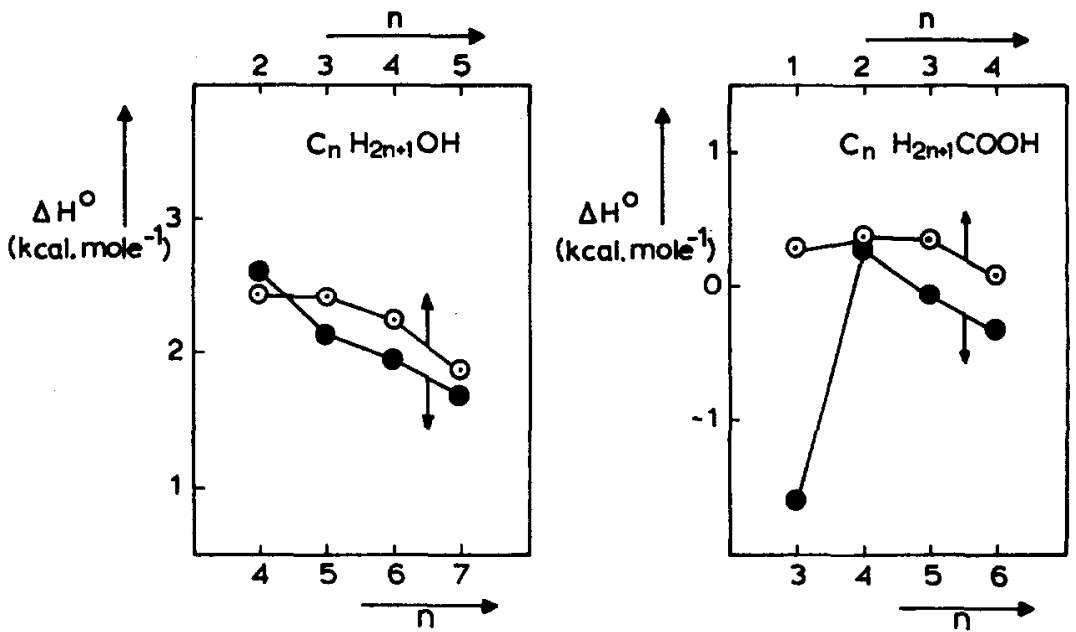

Fig. 8. $\Delta H^{\circ}\left(\mathrm{CH}_{2}\right)$ versus chain length for the transfer of alcohols and carboxylic acids from water to octyl-agarose (, this work) and from water to the pure liquids ( $O$, refs. 33 and 34$)$.

of homologous aliphatic ketones and esters from water to cyclohexane ${ }^{36}(-0.26 \mathrm{kcal}$ mole $^{-1}$ ).

Entropy values. Fig. 4 shows that $\Delta S^{\circ}$ values are positive for the three series and increase with increasing chain length. The contribution of a methylene group to the standard entropy change, $\Delta \Delta S^{\circ}\left(\mathrm{CH}_{2}\right)$, is almost the same in the three series for $n \geqslant 4$, being about 1.5 and $1.9 \mathrm{cal}^{\mathrm{mole}}{ }^{-1}{ }^{\circ} \mathrm{K}^{-1}$ for the alcohols at $\mathrm{pH} 3.52$ and $\mathrm{pH}$ 7.10 , respectively, and about $1.4 \mathrm{cal} \mathrm{mole}^{-1}{ }^{\circ} \mathrm{K}^{-1}$ for the carboxylic acids. Again, these values compare favourably with literature values pertaining to the transfer of alcohols from water to the pure liquids and of carboxylic acids from water to $n$ octane, as is demonstrated in Fig. 9.
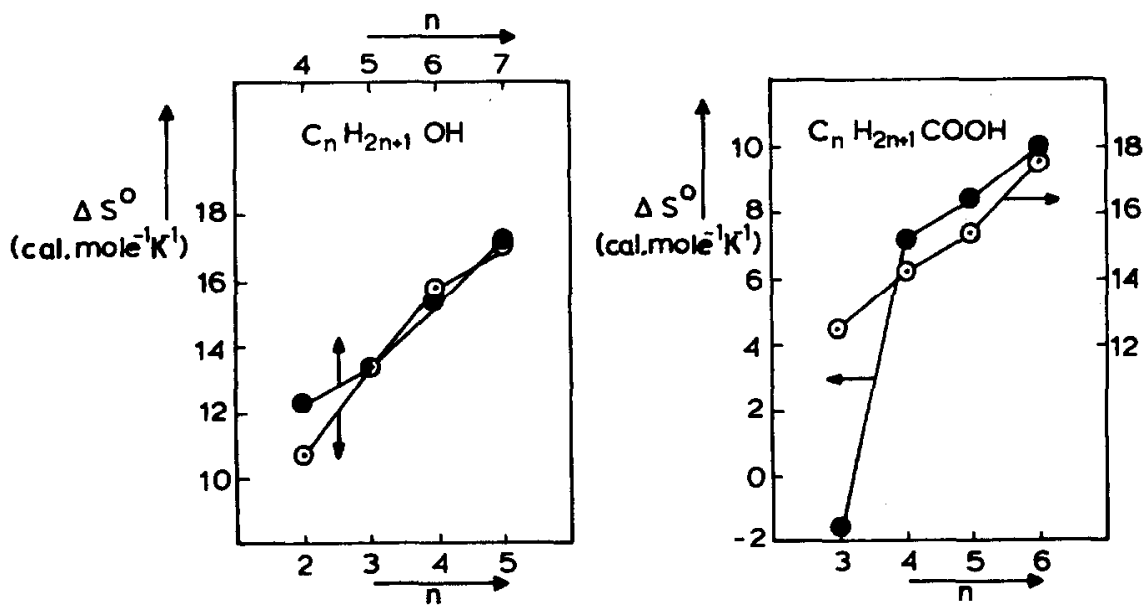

Fig. 9. $\triangle \mathrm{SS}^{\circ}\left(\mathrm{CH}_{2}\right)$ versus chain length for the transfer of alcohols and carboxylic acids from water to octyl-agarose ( $O$, this work), of alcohols from water to the pure liquids $(O$, ref. 25$)$ and of carboxylic acids to $n$-octane $(O$, ref. 35$)$. 


\section{REFERENCES}

1 H. S. Frank and M. W. Evans, J. Chem. Phys., 13 (1945) 507.

2 W. Kauzmann, Advan. Protein Chem., 14 (1959) 1.

3 H. P. Jennissen and G. Botzet, Int. J. Bial. Marcromol., 1 (1979) 171.

4 A. C. Haglund and N. V. B. Marsden, J. Polym. Sci., Polym. Lett. Ed., 18 (1980) 271.

5 S. Arnott, A. Fulmer, W. E. Scott, I. C. M. Dea, R. Moorhouse and D. A. Rees, J. Mol. Biol., 90 (1974) 269.

6 Octyl and Phenyl Sepharose CL-4B for Hydrophobic Interaction Chromatography, Pharmacia, Uppsala, 1976.

7 H. P. Jennissen, Biochemistry, 15 (1976) 5683.

8 R. Låås, Protides Biol. Fluids, Proc. Colloq., 23 (1975) 495.

9 S. Shaltiel, G. Halperin, Z. Er-El, M. Tauber-Finkelstein and A. Amsterdam, in O. Hoffmann-Ostenhof, M. Breitenbach, F. Koller, D. Kraft and O. Scheiner (Editors), Affinity Chromatography, Pergamon Press, New York, 1978, p. 141.

10 A. Amsterdam, Z. Er-El and S. Shaltiel, Arch. Biochem. Biophys., 171 (1975) 673.

11 T. C. Laurent and J. Killander, J. Chromatogr., 14 (1964) 317.

12 T. C. Laurent, B. Obrink, K. Hellsing and A. Wasteson, Progr. Separ. Purif., (1969) 199.

13 S. Waki, J. D. Harvey and A. R. Bellamy, Biopolymers, 21 (1982) 1909.

14 S. Hjertèn, J. Rosengren and S. Påhlman, J. Chromatogr., 101 (1974) 281.

15 J. Rosengren, S. Påhlman, M. Glad and S. Hjertén, Biochim. Biophys. Acta, 412 (1975) 51.

16 W. E. Hammers and C. L. de Ligny, J. Polym. Sci., 12 (1974) 2065.

17 S. Hjertén, Advan. Chromatogr., 19 (1981) 111.

18 W. J. Gelsema, C. L. de Ligny, W. M. Blanken, R. J. Hamer, A. M. P. Roozen and J. A. Bakker, J. Chromatogr., 196 (1980) 51.

19 S. Hjertén, in N. Catsimpoolas (Editor), Methods of Protein Separation, Vol. 2, Plenum Press, New York, 1976, Ch. 6, p. 233.

20 Cs. Horváth, W. Melander and I. Molnár, J. Chromatogr., 125 (1976) 129.

21 W. E. Hammers, G. J. Meurs and C. L. de Ligny, J. Chromatogr., 247 (1982) 1.

22 F. A. Vilallonga, R. J. Koftan and J. P. O'Connel, J. Colloid Interface Sci., 90 (1982) 539.

23 R. Aveyard and R. Mitchell, Trans. Faraday Soc., 65 (1969) 2645.

24 M. Goffredi and V. T. Liveri, J. Solution Chem., 10 (1981) 693.

25 C. Tanford, The Hydrophobic Effect, Wiley, New York, 1973, p. 20.

26 A. Leo, C. Hansch and D. Elkins, Chem. Rev., 71 (1971) 525.

27 C. Tanford, The Hydrophobic Effect., Wiley, New York, 1973.

28 G. E. Berendsen and L. de Galan, J. Chromatogr., 196 (1980) 21.

29 W. R. Melander and C. Horváth, Chromatographia, 15 (1982) 86.

30 W. E. Hammers, G. J. Meurs and C. L. de Ligny, J. Chromatogr., 246 (1982) 169.

31 M. C. Spanjer and C. L. de Ligny, J. Chromatogr., 253 (1982) 23.

32 A. Ben-Naim, Hydrophobic Interactions, Plenum Press, New York, 1980.

33 J. Konicek and I. Wadsö, Acta Chem. Scand., 25 (1971) 1541.

34 E. M. Arnett, W. B. Kover and J. V. Carter, J. Amer. Chem. Soc., 91 (1969) 4228.

35 R. Aveyard and R. Mitchell, Trans. Faraday Soc., 66 (1970) 37.

36 G. Della Gatta, L. Stradella and P. Venturello, J. Solution Chem., 10 (1981) 209. 